\title{
Community Learning Centers Program as an Educational Tool for Community Literacy Development in the Islamic Republic of Iran: Community of Golshan as a Case Study
}

\author{
Akbar Zolfaghari (Corresponding author) \\ Faculty of Human Ecology, University Putra Malaysia \\ No.17-14, Pangsapury Vista Impiana, Taman Bukit Serdang, Seksyen 10, 43300, Seri Kembangan \\ Selangor, Malaysia \\ Tel: 60-1-2264-6430Ｅ-mail: Akbar_zolfeghari@yahoo.com \\ Associate Professor Dr. Mohammad Shatar Sabran \\ Director of UPM Co-curriculum Centre, University Putra Malaysia \\ UPM Serdang, Selangor, 43400, Malaysia \\ Tel: 60-1-9220-9818, Fax: 60-3-8946-8557Ｅ-mail: Shatar@putra.upm.edu.my \\ Azam Zolfaghari \\ Payame Noor University: Kuala Lumpur Branch \\ No.6-5, Pangsapury Vista Impiana, Taman Bukit Serdang, Seksyen 10, 43300, Seri Kembangan \\ Selangor, Malaysia \\ Tel: 60-1-2264-6427Ｅ-mail: Azam_zol2009@yahoo.com
}

\begin{abstract}
Literacy plays an important role in Community Development (CD). Without literacy, people have difficulties improving their quality of life. Iran is no exception. Since the Islamic Revolution, the government of Iran has allocated great efforts and budgets on the literacy development to improve the quality of life. Following these efforts, the government has implemented various literacy programs. One of the major literacy programs that have been implemented for this purpose is the Community Learning Centers Program (CLCP). CLCP is the newest literacy program that has been implemented to develop literacy in order to improve the quality of life. CLCP has been emerged as a result of shortcomings of the previous literacy programs to solve the problem of illiteracy among people in the country. So far, the government of Iran has implemented 3517 CLCP into 3517 both rural and urban communities throughout the country. One of these rural communities is community of Golshan. Therefore, the main objective of this paper is to examine the role of CLCP in Community Literacy Development (CLD) in the community.
\end{abstract}

Keywords: Community Learning Centers Program, Community, Literacy, Development, Community Development

\section{Introduction}

Today, 9 million people are illiterates in Iran. Around 7 million illiterates population are adults age 10 and over. Most of illiterates mainly distributed in rural and remote communities. The community of Golshan is among of these remote and rural communities that had embraced illiterates.

However, in the community, the overall number of literates began to increase in recent years, because; CLCP has played an important role in improving the level of literacy among people in this community. CLCP initially was set up in the framework of UNESCO's Asia-Pacific Programme of Education For All(APPEAL)with the financial assistance of 
Japan and Norway in Asian and the Pacific Countries in 1998 (APPEAL, 2005). The government of Iran has launched the program in 2000. This program has covered uneducated, unskilled adolescents, unemployed educated and women in order to promote their literacy level and life skills(UNESCO, 2008).

One of the communities of the country that have been joined the program was community of Golshan. This community was selected as case study because of its literacy level. The community with the lowest literacy level and most privation was chosen. The community is situated $190 \mathrm{~km}$ north of Kerman state and $75 \mathrm{~km}$ northeastern of the Rafsanjan Township in Iran(Geographical Organization of Forces of Islamic Republic of Iran, 2005). The maps of community of Golshan in Iran and Kerman state are shown in the Figures 1 and 2. (Note 2)

According to the latest national statistics of Iran, total population of Golshan is 2090 people or 530 families. Most of the population is above 10 year old and the number of male population is outnumber the female population(SCI, 2006a, 2006b). Most of the population is involved in the agricultural activities. A few people also work in Anar (the nearest town and centre of the district) in the governmental and non-governmental sectors. Golshan is a part agricultural region known as Anar and has the most extensive area of agricultural land in Rafsanjan. Due to the vast agricultural activities, most of the Pistachio in the community is exported to the Asian and European countries. Besides farming, the people of Golshan are also involved in other income generating activities such as make paving blocks, bricks or wooden furniture. Few earn a living as building and construction laborers, welders and hairdressers(SCI, 2006a, 2006b).

There are several facilities in the community. Medical Center, Pharmacy, Private Medicine Doctor, Water Connections, Electric, Banks, Post Office, Telecommunication Company, Football Field, Basketball Court, Volleyball Court, Daily Markets, Computer Concierge Service, Fax Service, Internet Point, Laundry, Photography and Photocopier are among the facilities in the community.

In addition to that, several facilities for education are also available in this community namely Kindergarten, Primary, Guidance and Secondary Schools. Besides the formal schools, there is a non formal education center in the community for improving the literacy level. The center is known as Community Learning Center (CLC). CLC is a new type of community literacy development program that has been set up to develop the reading, writing and simple calculating skills among people in the community in 2003. There are several goals for CLCP in the community; however, the main goal of the program is to promote the level of literacy for improving the quality of life. In the context of Iran, all people who can read and write a text in Farsi (Persian) or in any other language, whether or not they had an educational certificate are literate(UNESCO Institute for Statistics, April 2008). Hence, in this community, a person is defined as literate if he/she can, with understanding, both read and write a short, simple statement on his everyday life(UNESCO Institute for Statistics, April 2008). In this paper, CLD means expansion of the literacy skills at communities level (Yopp \& Singer, 1994). The primary goal of CLD is to promote the quality of life among people at the communities' level. CLCP in the community of Golshan has been addressed as the most important tool for CLD. How and to what extent CLCP plays a role in CLD in the community are questions which should be answered in the following parts.

\section{Methodology}

To answer the questions, three types of data were collected; educators, learners and executives' data. Learners' data were collected from people who have participated in the program to learn literacy skills. Educators' data were collected from people who have participated in the program to teach illiterates. Executives' data were collected from people who have participated in the program to help both educators and learners in achieving their goals. The people were selected because they were involved directly with the CLCs. The respondents have been selected using the purposive sampling technique. There were two types of data that had been collected in this study. There were the primary and the secondary data. The primary data had been collected by having both Face to Face and FGD, while the secondary data had been collected through the printed and unprinted media, published and unpublished articles, journals, books, reports, and newspapers.

This was a qualitative analysis study. The results of this study had been analyzed qualitatively such as frequencies, and transcriptions of data gathered during the interview with the respondents. In this study, the qualitative aspects of the documents both published and unpublished had been summarized and classified according to the necessary data.

\section{Results of the Study}

Based on the results of the study, the CLCP was found highly effective in the community for solving the problem of illiteracy. The level of literacy in this community has improved through the program over the year especially after the implementation of the program. The level of literacy in Golshan before the implementation of CLCP was 74\%. The percentage, however, has increased to $94 \%$ four years after the introduction of CLCP in this community(Literacy Movement Department of Anar, 2007). The detail of community literacy development through CLCP in the community of Golshan during 2003-2007 is shown in the Table 1. (Note 1)

Based on the Table 1, it can be concluded that: the level of literacy in this community has been improved around $20 \%$ after the implementation of the program. The trend of the literacy level in Golshan after CLCP is portrayed in Figure 3. 


\section{(Note 3)}

As shown in Figure 3, the level of literacy in the community after CLCP has been continually increasing. This is due to the fact that, through CLCP, the people of the community are thought how to read, write, and do simple calculating. The literacy level in Golshan before the program in 2003 was $74 \%$ while the level has improved to $94 \%$ after the implementation of CLCP in 2007. Therefore, through CLCP, the literacy level among the community people have been increased about 20\%(Literacy Movement Department of Anar, 2007). All of the respondents of the study have agreed that CLCP made a significant contribution to the increase in the literacy level of the community through basic literacy, post-literacy and continuing education programmes. All the three different groups of the respondents believed that the role of CLCP was found to be positive in improving the literacy skills in this community.

Based on the results of the study, the efforts done by CLCP during four years ago have given the community to achieve the high level of literacy. Through CLCP, achievements on literacy had been obtained not in the areas of illiteracy eradication, but in post-literacy programmes, equivalency/complementary education, life skills and community development programmes that met the needs of the community people. The CLCP in the community had played a very important role in providing learning opportunities for the community people. After the implement of CLCP, a large number of people of this community have participated in literacy programmes. Examination of the activities implemented by CLCs showed that $79 \%$ of the participants were women.

As many respondents have referred, CLCP was able to call for support from local school and agencies and organizations to promote the level of literacy in the community. CLCP has improved the level of literacy among people in community of Golshan by conducting various educational programmes based on the community needs, establishing the structure and activities emphasizing the development and the evaluation of program objectives. The CLCP in the community could provide literacy opportunities for all, especially those who live in remote sub-communities.

Based on the results, since 2004, there have been several activities implemented for people of the remote sub-communities in this community. The CLCP has used the meeting halls of the community and schools as places in which their educational programmes are conducted. With the support from education service at this community and People's Committee, the CLCP has provided more educational opportunities to a wider variety of people in the community. In this community, CLCP has provided opportunities for individuals to acquire knowledge and life skills through structured activities and non-formal learning. The program environment also has encouraged all age groups living together in one community to make and follow their own educational plans and programs.

Through CLCP, the number of illiterate population has been continually decreased. The illiteracy level in the community before the program in 2003 was $26 \%$ while the level has decreased to around $6 \%$ in 2007 after the implementation of the program. From 2003 to 2007, around 400 people having successfully achieved at least some degree of literacy through CLCP however there are still approximately 120 illiterates in this community. Presently, Golshan with an adult population 2000 has around 1880 literate. This amount before the implementation of CLCP was 1480 people(Literacy Movement Department of Anar, 2007).

Based on the results of the study, the level of success in the program firmly was dependent on its activities, programs and its relationships with other very important factors such as community participation, government, international organizations, good educators and local leaders. Because of the success, the Literacy Movement Department of Anar has found that the CLCP model is useful to expand the literacy activities for developing the level of literacy among people in the community(Literacy Movement Department of Anar, 2007).

\section{Discussion}

The results of some studies such as Central Bureau of Statistics of Nepal; Horwood; Ministry of Education and Sports of Nepal, Statistics Indonesia, The National Statistical Office of Thailand have approved the results of the study. They confirmed that, CLCP has played a very significant role to promote the level of literacy not in Iran, but in the other participating countries as well.

For example, in Bangladesh, CLCP could help to increase the level of literacy. In the country, the level of literacy after the implementation of the program has improved around $23 \%$. The literacy level in the country before the implementation of the program was $26.1 \%$. The percentage, however, has increased to $49 \%$ seven years after the introduction of CLCP (Dhaka Ahsania Mission \& Department of Non-Formal Education, 2008; The Bangladesh Bureau of Statistics, 2008). Based on the Bangladesh' Statistics, The annual literacy growth level in the country was around 4\%.

Thailand has also successful experience in the program. In the country, CLCP has had important role in community literacy development. CLCP has presented the literacy activities within basic literacy, post-literacy and continuing education programs. In the country, the level of literacy has been promoted to $93.5 \%$ after the introduction of the program from $90.5 \%$ before the implementation of the program in the country. The literacy level in Thailand before the implementation of CLCP in the country was $90.5 \%$. The percentage, however, has increased to $93.5 \%$ seven years after the introduction of CLCP (Horwood, 2008; The National Statistical Office of Thailand, 2008). Based on the National 
Statistical Office of Thailand, the level of literacy in this country has been improved around 3\% after the implementation of the CLCP. The annual literacy growth level in the country was $0.40 \%$. Overall, although, the annual literacy growth level in the country was less than Bangladesh, however, the program in the country has had an encouraging role.

Besides Bangladesh and Thailand, CLCP has also played an effective role in Indonesia. The level of literacy growth in the country was higher than Thailand but less than Bangladesh. The annual literacy growth level was $1.2 \%$ in Indonesia. Through CLCP, people of communities in the country are insight how to read, write, and do simple calculating. The literacy level in this country has improved over the year especially after the implementation of the program. The literacy level in Indonesia before the implementation of CLCP was $78 \%$. The percentage, however, has increased to $86.8 \%$ seven years after the introduction of the program (Statistics Indonesia (BPS), 2008). Based on the Statistics Indonesia (2008), the level of literacy in this country has been improved around $9 \%$ after the implementation of the program.

In addition to three countries above, Nepal has also a successful experience in the case. In the country, CLCP has had a good role in educating the literacy skills namely reading, writing and simple calculating among the people in the communities. In the country, CLCP literacy programs have been implemented within basic literacy; post literacy, boys' and girls' literacy, and women education. These programs have improved the literacy level in this country over the year. The literacy level before CLCP in the country was $14 \%$. The percentage, however, has increased to $34.9 \%$ seven years after the program(Central Bureau of Statistics of Nepal, 2008; Ministry of Education and Sports of Nepal, 2008). Based on the Central Bureau of Statistics of Nepal, the level of literacy has been improved around $20.9 \%$ after the program. The annual literacy growth level in the country is around $3 \%$.

For instance, between 2002 and 2004, more than 1,600 illiterates have become literate by participating in CLCP literacy classes in Nepal. In addition to that, more than 1,300 children who dropped out of primary school have been provided basic education, and most of them have returned to school.

Therefore, in addition to Iran, in these countries, CLCP as an educational tool was successful in substantially increasing the literacy levels among community people, in encouraging them to be more enterprising, in enhancing their earning ability and empowerment, and finally in improving their overall socio-economic status in society.

\section{Conclusion and Recommendations}

Based on the discussions above, it can be concluded that; CLCP as educational tool has played very encouraging role in community literacy development in the community of Golshan in Iran. On the average, the level of literacy in the community has been promoted around $20 \%$ through CLCP during four years. On the overage, the annual growth level of literacy in this community is around 5\%.

It can also be concluded that: what make the program famous is not merely because of the successful roles that the program have implemented, but what it makes more interesting is the fact that success of the program was depended more on the presence of effective activities and its relationship with other important factors such as local leaders, community participation, international organizations, good educators and government. All of the factors worked together to the success of CLCP. Each factor has its own advantages and strengths. Removing one factor will retard the process of achieving success. One factor is no more or less important than the others. All of literacy activities in CLCP at this community have been implemented effectively with cooperation of these factors. Otherwise, CLCP alone was not able to achieve this success.

After reviewing the analysis and the holistic view of the results, the following recommendations will be the best to promote the level of literacy among people at other participating communities in CLCP.

1. Organizing the strategic planning in CLCP

2. Attention to the needs of communities in writing the new literacy textbooks.

3. Capacity building of the CLCP personnel

4. Change of the communities-perception towards literacy

5. Attention to the tongue language in literacy classes

6. Applying the new educational models in educating learners

7. Qualifying the literacy education and classes

8. Using new techniques such as media for learning.

\section{References}

Central Bureau of Statistics of Nepal. (2008). Statistical Year Book. [Online] Available: http://www.cbs.gov.np/statistical_year_book.php (Nov 2, 2008) 
Dhaka Ahsania Mission, \& Department of Non-Formal Education. (2008). The Community Learning Center in Bangladesh. [Online] Available: http://www.bbs.gov.bd/ (Nov 11, 2008)

Geographical Organization of Forces of Islamic Republic of Iran. (2005). Identity Certificate of Iran's Villages; Geographical Culture of Islamic Republic of Iran's Villages (10 ed. Vol. 112). Tehran: Geographical Organization of Forces of Islamic Republic of Iran, .

Horwood, J. (2008). Non-formal education in Thailand. [Online] Available: http://www.irfol.ac.uk/publications/pdfs/nonformaledthailand.pdf (Oct 28, 2008)

Literacy Movement Department of Anar. (2007). Activities of Literacy Movement Department of Anar. Anar: Literacy Movement Department of Anar.

Ministry of Education and Sports of Nepal. (2008). Educational Statistics of Nepal. [Online] Available: http://www.moe.gov.np/moe/stats/stat_nfec.php (Nov 2, 2008)

SCI. (2006a). National Population and Housing Census. [Online] Available: http://amar.sci.org.ir (Retrieved Oct 16, 2008)

SCI. (2006b). Statistical Yearbook of Iran. [Online] Available: http://amar.sci.org.ir (12-1-2008, 2008)

Statistics Indonesia (BPS). (2008). Statistical Yearbook of Indonesia 2007. [Online] Available: http://www.bps.go.id/ (Nov 13, 2008)

The Bangladesh Bureau of Statistics. (2008). Statistical Yearbook of Bangladesh 2007. [Online] Available: http://www.bbs.gov.bd/ (Nov 13, 2008)

The National Statistical Office of Thailand. (2008). Statistical Yearbook of Thailand 2007. [Online] Available: http://www.nfe.go.th/en.htm (Nov 13, 2008)

UNESCO. (2008). Overview of CLCs. [Online] Available: http://www.unescobkk.org/index.php?id=244 (May 23, 2008)

UNESCO Institute for Statistics. (April 2008). Literacy and Adult Education Statistics Programme. [Online] Available: http://portal.unesco.org/education/en/files/41640/11254982355Metadata_Literacy_08_2005.xls/Metadata_Literacy_08_ 2005.xls (Feb 7, 2009)

Yopp, H. K., \& Singer, H. (1994). Toward an interactive instructional reading model:Explanation of activation of linguistic awareness and met linguistic ability in learning to read. In H. Singer \& R. B. Ruddell (Eds.), Theoretical Models and Processes of Reading (4 ed., pp. 381-390). Newark, Del: International Reading Association.

Note 1. The Table below shows the detail of community literacy development through CLCP in the community of Golshan during 2003-2007.

Table 1. Literacy level in Iran after CLCP

\begin{tabular}{|c|c|c|}
\hline Year & Literacy Level (\%) & Illiteracy Level (\%) \\
\hline 2003 & 74 & 26 \\
\hline 2004 & 83 & 17 \\
\hline 2005 & 88 & 12 \\
\hline 2006 & 90.5 & 9.5 \\
\hline 2007 & 94 & 6 \\
\hline
\end{tabular}

Source: (Literacy Movement Department of Anar, 2007) 
Note 2. Figures 1 and 2 show the maps of community of Golshan in Iran and Kerman state.

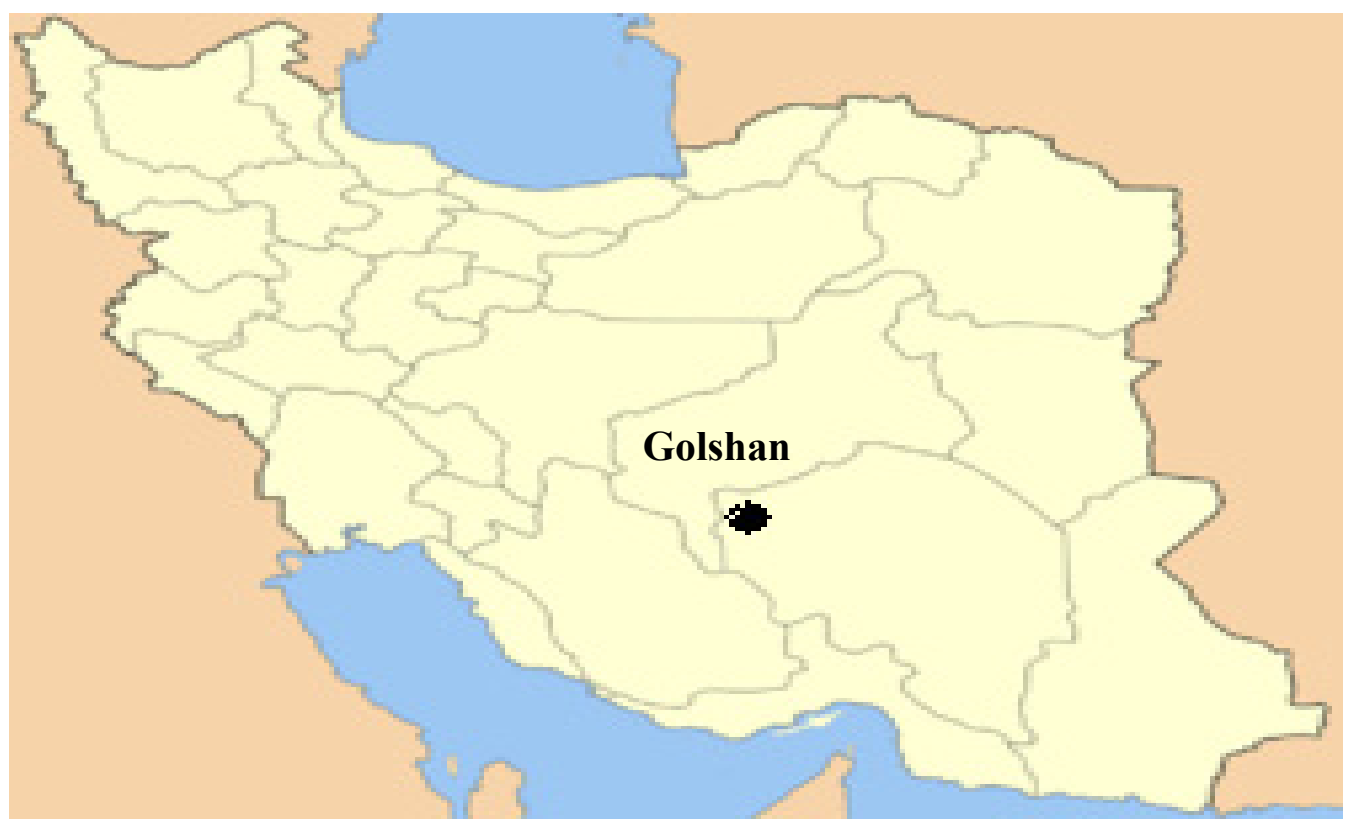

Figure 1. The Map of Community of Golshan in Iran

Source: (Geographical Organization of Forces of Islamic Republic of Iran, 2005)

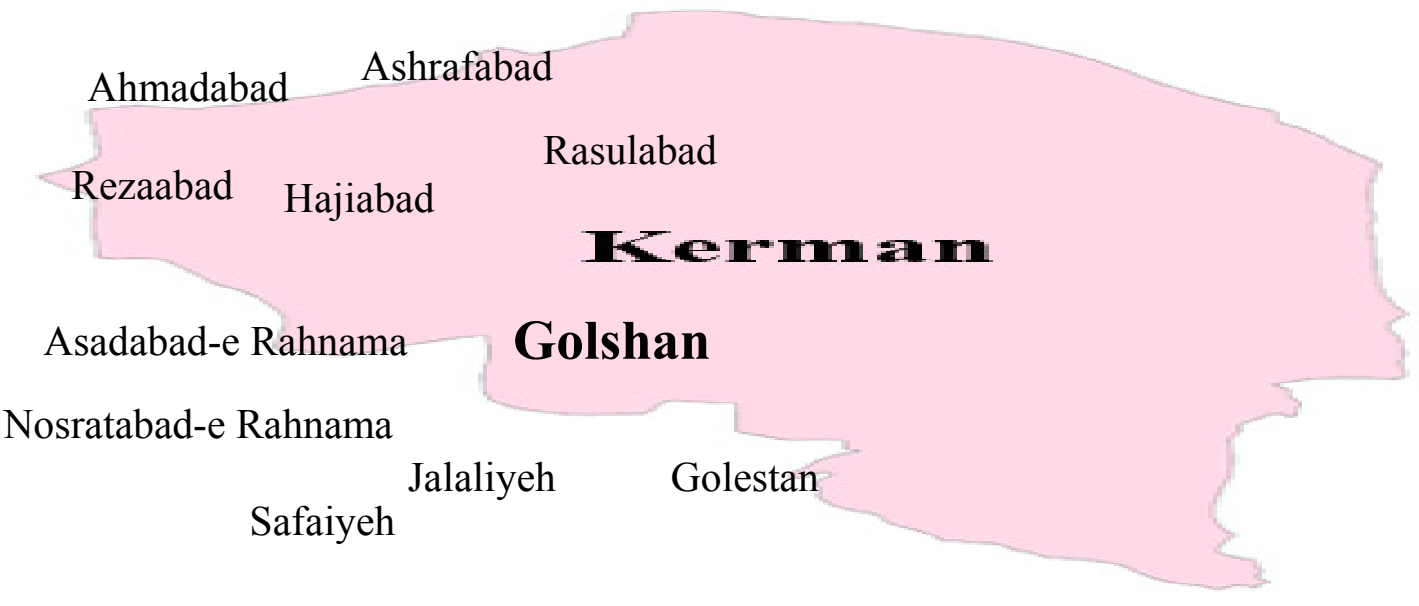

Figure 2. The Map of Community of Golshan in Kerman State

Source: (Geographical Organization of Forces of Islamic Republic of Iran, 2005) 
Note 3. Figure 3 shows the trend of the community literacy level in Golshan after CLCP

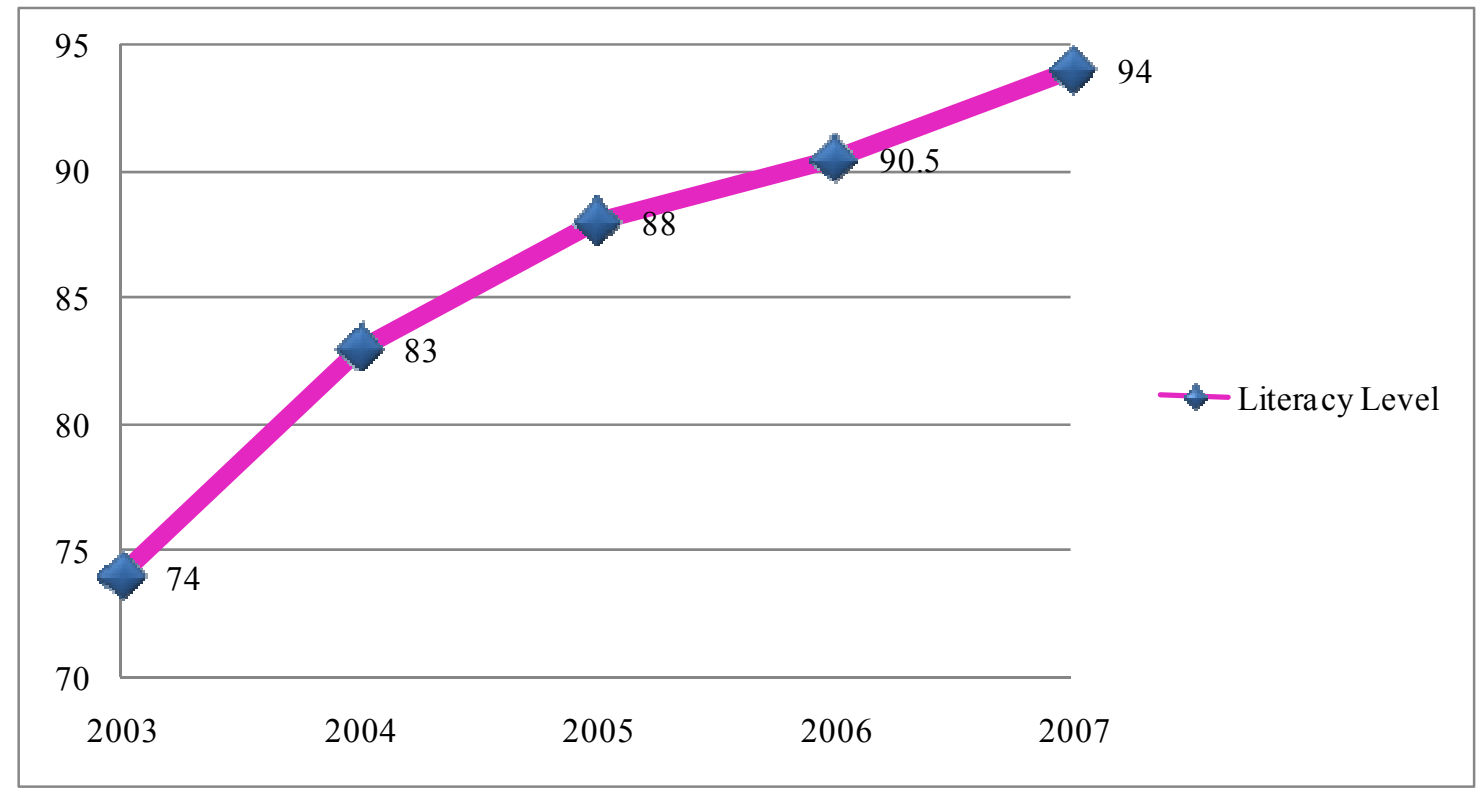

Figure 3. The Trend of Community Literacy Level in Golshan after CLCP

Source:(Literacy Movement Department of Anar, 2007) 